\title{
Memórias de escritores do Brasil na Academia Real da História Portuguesa
}

\author{
Adma Fadul Muhana
}

RESUMO: Os anos de 1720-1730 assistem a uma mudança de paradigmas no que diz respeito ao registro da memória e ao lugar dos escritores na constituição de uma memória coletiva. TrabaIhos consistentes têm enfatizado o papel da Academia Real da História Portuguesa (fundada em 1720), cujos princípios de memorialização passaram a dominar a escrita da história, como um processo de coleta e ordenação de documentos e notícias. As investigações da Academia, porém, tinham um escopo bem mais abrangente do que a mera recolha de dados, tendo por finalidade a construção de uma historiografia portuguesa, no âmbito da corte de d. João v. Neste sentido, encomendaram um inventário dos escritores existentes nos domínios portugueses, como no Brasil e na Índia, e produziram registros de memórias dos que existiram.

PALAVRAS-CHAVE: Escritores, Academia Real da História Portuguesa, Brasil, séculos xvil-xviII.

\begin{abstract}
The years 1720-1730 witness a paradigm shift in the recording of memory and the place of writers in the constitution of a collective memory. Consistent works have emphasized the role of the Royal Academy of Portuguese History (founded in 1720), whose memorisation principles came to dominate the writing of history, as a process of collecting and inventing documents and news. The Academy's investigations, however, had a much broader scope than mere data collection, aiming at the construction of a Portuguese historiography, within the scope of the court of $d$. John v. In this sense, they commission an inventory of writers in Portuguese domains, as in Brazil and India, and produce records of memories of those that existed.
\end{abstract}

KEYWORDS: Writers, Royal Academy of Portuguese History, Brazil, $17^{\text {th }}-18^{\text {th }}$ centuries. 


\section{A ACADEMIA REAL DA HISTÓRIA PORTUGUESA}

Os anos de 1720-30 assistem a uma mudança de paradigmas no que diz respeito ao registro da memória e ao lugar dos escritores na constituição de uma memória coletiva. Trabalhos consistentes têm enfatizado a atuação da Academia Real da História Portuguesa (fundada em 1720), cujos princípios de memorialização passaram a dominar a escrita da história, como um processo de coleta, inventarização e interpretação de documentos e notícias. ${ }^{1}$ Evidentemente, as investigações da Academia tinham um escopo bem mais abrangente do que a mera recolha de dados, tendo por finalidade "a construção da memória histórica dos seus domínios ultramarinos,", ${ }^{2}$ no âmbito da corte de d. João v.

O primeiro intuito da Academia Real foi a redação de uma História eclesiástica, porém na própria proposição dela, firmada pelo Rei, estava posto que esse fim seria alargado para o de uma História Portuguesa lato sensu:

Tenho resoluto que se estabeleça hua Academia em que se escreva a Historia Ecclesiastica destes Reynos, e depois tudo o que pertencer a toda a Historia delles, e de suas Conquistas. $^{3}$

Visando a esse objetivo, além dos cinquenta "acadêmicos do número da Academia", foram designados acadêmicos supranumerários, colaboradores nas províncias e nos territórios ultramarinos, que pudessem transmitir à Academia informações fidedignas acerca de documentos, testemunhos, livros, bibliotecas, escritores etc. De posse desses arquivos, caberia aos acadêmicos redigir o que do passado português deveria ficar registrado para a posteridade. A Manuel Caetano de Sousa, principal entre os Acadêmicos, além da redação em língua latina da História Eclesiástica de Lisboa, tam-

1. KANTOR, Íris. Esquecidos e renascidos. Historiografia acadêmica luso-americana. 1724-1759. São Paulo: Hucitec; Salvador: Centro de Estudos Baianos/UfBA, 2004. Ver também мотA, Isabel Ferreira da. A Academia Real da História. Os intelectuais, o poder cultural e o poder monárquico no séc. XVIII. Coimbra: Minerva, 2003; e Sara Bravo Ceia, Os Académicos Teatinos no tempo de d. João v: Construir saberes enunciando poder. Dissertação de Mestrado em História Moderna e dos Descobrimentos. FCSH - Universidade Nova de Lisboa, 2010.

2. KANTOR, Íris. Op. cit., pp. 19 e 77 ss.

3. Colecçam dos documentos estatutos e memorias da Academia Real da Historia Portugueza, vol. 1, 1721. 
bém cabia escrever acerca das Vidas dos Papas, Cardeais e Bispos que tiveram diocese fora de Portugal; a Pedro Monteiro, da Ordem dos Pregadores, as Memórias em língua portuguesa para a História da Inquisição; quanto à História secular, Lourenço Botelho Sottomayor estava designado para compor em português as memórias para a história das antiguidades de Portugal até a conquista dos Romanos; a Diogo Barbosa Machado cabia compor na língua portuguesa as memórias do rei dom Sebastião até a Aclamação; a própria História da Academia seria composta pelo conde de Villarmayor etc. Para tanto, os estatutos estabeleciam um conjunto de questões a serem feitas às dioceses e comarcas com o fim de se escreverem as referidas histórias, recomendando "Que mandem as noticias dos Religiosos das suas Ordens que fiseraõ alguns livros, ainda que os naõ imprimissem, declarando as suas patrias, e mortes". ${ }^{4}$

É nesse sentido, e a partir dos códices existentes, que podemos constatar o esforço da Academia como um todo para a elaboração de um catálogo geral de autores portugueses - eclesiásticos e seculares. As notícias de que dispomos - e das quais a Biblioteca Lusitana de Diogo Barbosa Machado é um dos mais importantes frutos - deixam entrever um complexo desenvolvimento dessa empresa, para a qual outros trabalharam. Dos acadêmicos que também se empenharam na tarefa, um dos mais atuantes foi $\mathrm{d}$. Francisco de Almeida Mascarenhas. Eleito em 1728 como responsável pela "Disciplina e Ritos Eclesiásticos", d. Francisco também se dedicou a recolher dados que lhe permitissem compor uma Biblioteca Hispana e Lusitana. Por ocasião da sua morte, em 1745, havia coletado quarenta volumes manuscritos de informações biobibliográficas de autores, como o demonstra o catálogo da sua Livraria particular. ${ }^{5}$ Muitos códices da Biblioteca Nacional de Portugal referentes a esse assunto trazem correspondência de d. Francisco de Almeida com personagens do Reino e das Províncias, no sentido de obter informações acerca dos escritores e suas obras. ${ }^{6} \mathrm{~A}$ maior parte delas refere-se a

4. No primeiro volume da Coleção das atas... (1721), capítulo intitulado (s/p) "Reflexoens sobre o estudo academico".

5. No Elogio do Excelentíssimo e Reverendíssimo Senhor Dom Francisco de Almeida Mascarenhas, publicado no ano da sua morte (1745), Francisco Joseph Freire registra, entre os escritos de d. Francisco de Almeida, a Bibliotheca Hispana, e Lusitana, afirmando que "passão de 40 os volumes de memórias para esta Obra" (p. 50). No Catalogo da Livraria que ficou por fallecimento do Excelentis. e Reverend. Senhor Principal d. Francisco de Almeyda Mascarenhas (publicado sem data nem local de impressão), constam ao menos cinco tomos que pertenceriam a tal Biblioteca.

6. Do meu conhecimento, os códices 625, 908, 909, 910 e 7187. Ver Manuela D. Domingos, "Erudição 
autores eclesiásticos - não só por ser um fito da Academia a redação de uma história eclesiástica, como por serem as ordens religiosas as que acolhiam a maior parte dos letrados e que mantinham arquivos -, mas também a escritores seculares e poetas. Neste sentido, sócios supranumerários da Academia centralizavam nas províncias as informações requeridas, a partir de uma extensa rede de informantes. O que rege o trabalho da Academia é, criticamente, inserir esses escritos heteróclitos numa única e grandiosa biblioteca portuguesa, mesmo que, chegando a Lisboa, eles se percam, ou sejam apropriados por outros, sejam impressos deslocados, fragmentados, ou ressignificados. As memórias coletadas por d. Francisco, aliás, acabaram incorporadas à Bibliotheca Lusitana de Barbosa Machado.

Assim, a princípio, a visada da Academia Real de História Portuguesa é enciclopédica, inventarista, e seu alvo é uma busca detalhada, mas específica, de informações que componham as coleções de autores (e lugares, e eventos, e edifícios). No caso dos escritores, os informantes são interrogados a partir de uma lista específica de topoi personarum: nome; pais; local de nascimento; ofício; data de profissão, quando religioso; data de falecimento; título das obras; testemunho de se estão impressas, ou manuscritas e, neste caso, quem é seu possuidor. Os códices da Biblioteca Nacional de Portugal consultados apresentam estágios diversos desse elenco, mesclando informações provindas de localidades do Reino, Brasil e Índia. Por exemplo, no códice 908, que aglutina documentos enviados a d. Francisco de Almeida em 1738, após um Cathalogo dos Escritores da Companhia de Jesus da Provincia do Brazil (fls. 150-161) e de um Mapa, e Memorias dos Padres Claustraes da Milicia de Christo Reformada (fls. 167-179) apresenta um conjunto que trata de autores do Estado da Índia.

É possível que o pedido de informações aos acadêmicos supranumerários - cujos termos desconhecemos - não fosse claro acerca do que se devia entender por escritores de uma "Biblioteca Lusitana" - o que não se há de estranhar, uma vez que sua definição é ainda objeto de discussão nos estudos pós-coloniais. O conceito que regia o princípio das listas não seria evidente para aqueles que deveriam compô-las. O certo é que, seja nas listas de autores do Brasil, seja nas da Índia, encontramos correspondentes que elaboram seus róis a partir de critérios díspares: em alguns, o destaque vai para a ordem religiosa a que o autor pertence, independentemente do local de nascimento; em outros, a "pátria"

no tempo joanino: a livraria de d. Francisco de Almeida”. Leituras. Revista da Bib. Nac. de Lisboa, n. 9-10, 2001, pp. 191-219. 
é determinante, sendo referidos apenas aqueles que nasceram no lugar; e, finalmente, outros arrolam todos os que escreveram no lugar em questão. Os conjuntos se interceptam e exibem a pluralidade de pertencimentos identitários na monarquia portuguesa do Setecentos. Assim é o escrito coletâneo relativo à Índia presente no códice 908, o qual é composto por três elencos: uma Memoria dos Escritores desta Provincia do Apostolo Sã̃ Thome da Regular observancia de N. P. S. Francisco, e dos da Madre de Deus reformados, anônima (fólios 184-185); uma Reposta aos Interrogatorios impressos de como se há de dar noticia dos Authores e dos livros impressos, e naõ impressos, que sabemos redigida por fr. Faustino da Graça (fls.189-191v); $;$ e uma Resposta aos Interrogatorios remettidos pello Exmo. Sr. Conde da Ericeira d. Luis de Meneses a Pedro da Sylva, e Alva [...] sobre a noticia que se poude descobrir dos Authores naturaes da India dos dominios do Reino de Portugal (fls. 192-202). Pedro da Silva e Alva, ${ }^{8}$ que redige a última listagem, esclarece sua concepção: "Adverti que nos interrogatorios remettidos se desejaõ noticias dos AA naturaes do Reino e suas conquistas; porem não se pedem dos AA naturaes do Reino que compuserão na India, e assim so remetto as noticias dos AA naturaes, ou filhos da India". [fl.194v]

Diferia, assim, do seu antecessor no códice, fr. Faustino da Graça, que arrolara escritores originários de diversas partes do Reino que haviam atuado na Índia. E diferia também de quem antecedera a ambos, anônimo, que coletara informações exclusivas dos membros da ordem franciscana que missionaram na Índia. A heterogeneidade dos escritos é posteriormente aplanada na ausência de hierarquia aparente que o critério aleatório, como de um dicionário de verbetes, fornece à Bibliotheca Lusitana.

\section{CATÁLOGOS DE ESCRITORES DO BRASIL}

O mesmo ocorre nas listas do Brasil. No códice 908 encontramos catálogos de escritores pertencentes a ordens eclesiásticas - os quais seguem a divisão das "províncias" de

7. Fr. Faustino da Graça é referido por Barbosa Machado como natural de Goa e por ter se distinguido "dos seos domesticos em a cultura das letras, e observancia dos preceitos do seu instituto".

8. A principal referência que dele temos encontra-se em José F. Ferreira Martins, História da Misericórdia de Goa (1621-1910), Goa, Imprensa Nacional da Índia Portuguesa, 1912, p. 11 e 109-10, segundo o qual Pedro da Silva fora eleito provedor da Misericórdia de Goa por meios fraudulentos, razão por que o governador teria mandado prendê-lo em 1742. O enunciado é reproduzido por RUSSELL-WOoD, A. J. R. Fidalgos and Philanthropists: The Santa Casa da Misericórdia of Bahia, 1550-1755, p. 27. 
cada Ordem - e seculares: Catalogo dos Escritores da Companhia de Jesus da Provincia do Brazil (fl.150-161); Memorial dos Religiosos escritores [da Provincia Capucha da Imaculada Conceição de N. Sra. no Rio de Janeiro...] que compuserão tanto em Prosa, como em verso (fls. 227-240v); Escritores da Companhia de Jesus no Estado do Maranhão (fls. 245-246v); Cathalogo de alguns escritores desta Capitania do Grão Pará (fls. 289293v) e Cathalogo dos Poetas que florecerão na Cidade da Bahia (fls. 333-336v). Como veremos, a presença eclesiástica em nada obsta a fusão com os saberes científicos que, de modo algum, são desconhecidos dos novos letrados, acadêmicos, ou que gravitam em torno das Academias.

A primeira listagem, o Catalogo dos Escritores da Companhia de Jesus da Provincia do Brazil, de autoria do Reitor do Colégio da Bahia, pe. Plácido Nunes, apresenta vinte escritores da Companhia atuantes no Estado do Brasil, alguns dos quais citados na Bibliotheca Luzitana de Barbosa Machado, por "pertencerem" ao Reino: os padres Alexandre de Gusmão, Antônio Vieira, Francisco de Mattos, Lourenço Craveiro, Antonio de Sá, Mateus de Moura, Simão de Vasconcelos (Chronica da Companhia de Jesus do Estado do Brazil e do que obraram seus filhos nesta parte do novo mundo)'; Ângelo dos Reis (tinha tratado de mais perto, e interiormente ao P. Antonio Vieira, de quem foi escrevente por algum tempo); Bartholomeu de Leão (Catecismo brasílico da doutrina cristã, em tupi-guarani); Domingos Ramos (hum tomo justae magnitudinis de Probabilitate); Euzebio de Mattos (hum tratado de Merito); Pedro Dias (Arte da Lingua de Angola [quimbundo]); Prudêncio do Amaral (huma Ecloga em verso heroico de Opificio mellis [... imperfeita, em verso Elegiaco, Ars amandi Deiparam). Porém, lista também escritores jesuítas que missionaram no Brasil, embora de outras naturalidades: os padres João Antonio Andreoni (Pia Hilaria), Valentim Estancel (Epigrãmas, a que intitulou Jocoseria) e George Benci, italianos do grupo oponente ao de Vieira; Antonio Maria Bonnuci, também italiano, secretário de Vieira; José de Anchieta, das Canárias; Luis Vicencio Mamiani (Arte de gramatica e Catecismo em língua brasilica da nação dos Kiriri), italiano. Na carta de encaminhamento do Catalogo, datada de junho de 1738, o pe. Plácido Nunes informa a d. Francisco que o religioso que o organizou (ele mesmo) o fez segundo "o methodo, que observâraõ na nossa bibliotheca os PP. Ribadaneyra,

9. As notícias acerca dos manuscritos provêm de outra carta do pe. Nunes, datada de outubro de 1739, no cód. 1787 . Ver infra. 
Alegambe, e Sotuello" (fl. 148). ${ }^{10}$ No ano seguinte, enviará a d. Francisco uma lista adicional de escritores contendo, entre outras memórias, os nomes dos padres Antonio de Andrade (hum curso de Philosophia), Antonio Barboza (hum tratado de Fide), João Matheos Faletti (hum tratado, no qual apoiava a opinião do grande Pe. Antonio Vieyra no famozo livro do Clavis Prophetarum), Mathias de Andrade (de scientia Media, de Praedestinatione) e Luis Carvalho (hum livrinho de epigrãmas a Virgem Senhora). A incompletude é própria dessas listas bibliográficas.

A segunda lista, o Memorial dos Religiosos franciscanos do Rio de Janeiro, é composta por fr. Apolinário da Conceição, que a redige em Lisboa, em 1737, com o fim declarado de agregá-la à Bibliotheca Hispana, e Lusitana, de d. Francisco de Almeida. Fr. Apolinário, que se insere em sexto lugar entre os doze franciscanos que enumera, é uma personagem singular. ${ }^{11}$ Não obstante ser leigo e ter vivido seus vinte últimos anos na corte, fr. Apolinário não deixou de manter

su filiación institucional a la provincia franciscana de Río de Janeiro (de la que, incluso, llegó a ser cronista), atender los intereses y necesidades de sus hermanos de la América portuguesa y, en último término, conservar una comunicación fluida con los contextos coloniales que emplearía en beneficio de su actividad como escritor. ${ }^{12}$

Estudioso prolífico, suas obras concentram-se em livros de devoção, histórias da Ordem franciscana e hagiografias, em particular os Pequenos na Terra, grandes no Ceo (17321745, em cinco vols.), que consistem em um compêndio de notícias dos religiosos leigos da Ordem Seráfica. Sua "erudição religiosa" e sua familiaridade com mercadores de livros e livreiros permitiram-lhe desempenhar o ofício de correspondente entre Lisboa e Rio de Janeiro, adquirindo livros para serem enviados à sua província, bem como recebendo escritos para serem impressos na corte. Todos esses aspectos encontram-se nas "advertências" que faz ao fim do seu Memorial, nas quais se mostra que, ao cum-

10. O padre Petro Ribadaneira compôs uma Bibliotheca scriptorum Societatis Iesu, em 1602, a qual foi ampliada pelos padres Philippe Alegambe, em 1642, e Nathanaele Sotuello, em 1675.

11. As informações de que dispomos provêm do artigo de Federico Palomo, "Conexiones atlánticas: Fr. Apolinário da Conceição, la erudición religiosa y el mundo del impreso en Portugal y la América portuguesa durante el siglo XVIII", Cuadernos de Historia Moderna, 2014, Anejo XIII, 111-137.

12. Idem, p. 114 . 
prir o trabalho que lhe é demandado pela Academia, fr. Apolinário se vale da oportunidade para exibir os manuscritos de que dispõe e suas qualidades. Adverte, assim, que conserva manuscrita a aprovação que seu confrade, fr. Ubaldo da Visitação, fizera para os Pequenos na terra, e Grandes no Ceo, a qual não se dera à luz "por particulares respeitos" - supondo nós que tais respeitos se relacionem às contendas de fr. Ubaldo com o arcebispo de Goa, Inácio de Santa Teresa, que o destituiu do seu cargo, acusando-o de responsável por desordens na Índia; adverte também que o livro de Simão Ferreira Machado intitulado Triunfo Eucarístico foi impresso em Lisboa "por cuidado de Religioso de minha Provincia assistente nesta corte" - possivelmente ele mesmo, fr. Apolinário da Conceição, que desde 1733 se estabelecera em Lisboa. ${ }^{13} \mathrm{E}$, ainda, que conservava manuscrito um sermão do padre jesuíta José Mascarenhas pronunciado na festividade das canonizações de S. Jácome de Marca e S. Francisco Solano, no Rio de Janeiro, em 1726, "o qual intento se imprima junto com outras notícias da mesma festividade". José Mascarenhas foi um dos que, nos anos de 1720, se agregaram à comitiva do governador das Minas, o conde de Assumar (irmão de d. Francisco de Almeida), e aí difundiu escritos de Vieira. ${ }^{14}$

Entre os escritores capuchos mencionados por fr. Apolinário, ${ }^{15}$ merece destaque fr. Cristóvão de Jesus Maria, que, em 1734, redigira uma sebastianista Historia Inopina Lusitana. Sucessos notáveis do valor de nossos antigos continuando nos presentes, e futuros Portuguezes com os sucessos concernentes aos tempos. Atenuação da décima-sexta geraçaõ, e na mesma com o Respiciam do Senhor estabelecido o Quinto, e Universal Imperio do Mundo. Dedicado ao illustre, e invicto Capitaõ da Infantaria, Protector de Portugal, Advogado contra a peste, e Martir de Christo S. Sebastião - cujo paradeiro se desconhece. Longe de ser uma exceção, a presença de escritos providencialistas, em que se destaca a leitura de Vieira, mostra que a história da América Portuguesa está enraizada nos mesmos tópicos da história reinol.

\footnotetext{
13. Idem, p. 120.

14. Ver romeiro, Adriana. Um visionário na corte de d. João v: revolta e milenarismo nas Minas Gerais. Belo Horizonte: UFMG, 2001. Por desconhecer esse sermão, a autora transmite a informação de Inocêncio da Silva, segundo o qual o pe. Mascarenhas, não citado por Barbosa Machado, deixara escrita apenas uma "Interpretação acerca das letras de uma inscrição" (p. 154 e 247).

15. São eles os frades: Agostinho da Conceição, Agostinho da Trindade Seixas, Antônio de Santa Maria, Caetano de Belém, José dos Anjos, Manoel do Desterro, Manoel da Encarnação e Miguel de São Francisco, além de dois anônimos.
} 
Nesse sentido, vale a pena apontar um correspondente de fr. Apolinário da Conceição, que comparece também no códice 908. Trata-se de uma personagem singular, o médico Mateus Saraiva, físico-mor do Presídio do Rio de Janeiro, médico e cirurgião-mor da mesma Capitania, onde também foi membro da Academia dos Felizes (1736-1740). Em 1738, Mateus Saraiva enviou do Rio de Janeiro uma carta a fr. Apolinário da Conceição dando conta dos seus estudos "a fim de se passarem à Biblioteca Hispana, e Luzitana", em resposta à que o frade lhe remetera em nome da Academia Real, instituição à qual o médico almeja pertencer:

Meu Amigo e Senhor: muitos effeytos temos observados que parecem ser sustancias predeterminadas do Destino, e não sucessos julgados por Acaso, sem fim acontecido. Isto digo; porque escrevendo ha 3 mezes, ao R. P. Mestre Ignacio Rodriguez, Irmão de Alexandre de Gusmão, Religioso da Companhia, para que me insinuasse o que seria prescizo para conseguir da Academia Real da Historia o ser hum dos Provinciays Academicos nesta America, acheyme ao mesmo tempo (com poca differença) com hum Papel da mesma Academia, enviado por meyo de V. P. pera dar conta dos meus estudos, a fim de se passarem à Biblioteca Hispana, e Luzitana; e tambem dos que pudesse alcançar, feytos pelos Nacionays nestas Conquistas. [fl. 310]

Na carta, Mateus Saraiva não envia notícias de escritores "nacionais nestas conquistas", mas faz uma relação dos seus próprios manuscritos, os quais podem acreditá-lo na Academia Real, à semelhança do que - diz ele - ocorrera com Sebastião da Rocha Pitta, embora oferecendo menos. São elas: a Ilustração da América Portuguesa; a Medicina Brasílica; os Desempenhos da Medicina, Desagravos de seus professores; e a Instrução políti$c a$, além de duas Orações acadêmico-panegirísticas. ${ }^{16}$ Todos esses escritos (excetuando-se a Instrução política) são referidos por Barbosa Machado, a quem Mateus Saraiva também escreverá em 1742, ${ }^{17}$ tendo-o pelo acadêmico que poderá introduzi-lo na Academia Real.

16. Estas Orações - bem como um Discurso ascético-acadêmico e crítico, um Epítome históricoacadêmico (que resume a Ilustração da América Portuguesa) e os textos introdutórios a um Parnaso festivo em louvor às fundadoras do Convento de N. Sra. da Ordem Seráfica no Rio de Janeiro - são as únicas obras conhecidas de M. Saraiva, transcritas por Aderaldo Castello, em O movimento academicista no Brasil, vol. I, t. vi, pp. 7-52 e 59-73.

17. A carta de M. Saraiva a Barbosa Machado também foi transcrita por A. Castello, op. cit., vol. I, t. vi, pp. 53-8. 
Ao compartilhar com fr. Apolinário da Conceição suas expectativas, Mateus Saraiva mostra-se como um acadêmico da Província cujos estudos o habilitam a pertencer às agremiações científicas e literárias europeias, ofertando-lhes memórias e notícias do Novo Mundo. Um arraigado providencialismo se exibe a cada frase do médico, apoiado em uma argumentação com intrusões científicas e dialética, em que as tradições valem menos do que os testemunhos histórico-naturais. Tudo isso se lê na descrição da Ilustração da América Portuguesa que Saraiva apresenta a fr. Apolinário:

Toda a Relação fica feyta em dez folhas de papel, e com argumento do o que nos queremos fazer acredor [...]. Não a remetemos pelo perigo a que esta carta vay exposta; e como a Primeyra Obra he toda por Dissertaçoens, criticas, e Anticriticas, pera melhor persuadir o que pertendemos fazer scientifico, e não conjectural somente por Tradicçoens, esperamos o atendido dos Doutos pelo attendivel da materia: relevante por natureza, e por Monumentos // do Primeyro Seculo desta Idade de Christo, ou Sexta. [fls. 310v e 313]

Apesar da intrincada sintaxe, entendemos que a tal Relação consiste no "Epítome histórico-acadêmico" (proferido na Academia dos Felizes), em que Saraiva discorre em detalhes acerca da sua Ilustração, em cuja primeira parte ("História Sagrada") trata da promulgação da Lei da Graça por São Tomé - matéria tão contenciosa, diz ele, que um erudito da Academia Real de História evitara dar seu parecer antes de ver "a decisão da Cúria onde se disputa atualmente na oposição que se faz ao livro Clavis Prophetarum $" .{ }^{\prime 18}$ A novidade da sua asseveração, diz Mateus Saraiva, está em que ela se baseia não em Tradições, mas em um Monumento para a posteridade inscrito numa Pedra erigida na Serra Itaguatiara ao Sul de Ouro Preto, em que se acham Figuras simbólicas, semelhantes às que João de Barros e Diogo do Couto identificaram na Ásia, e que o padre Atanásio Kirker interpretara no Oriente. ${ }^{19}$ Tal monumento identificável no Brasil é datável da Sexta Idade - a qual, segundo o cômputo milenarista, designa a que prenuncia o Quinto Império. Mateus Saraiva afirma poder demonstrar ainda que a América Portuguesa deve ser considerada uma das regiões Ofirinas, aonde as frotas salomônicas vinham a cada ano e de onde levavam "Ouro,

18. O acadêmico Manuel Dias de Lima assim se pronuncia em conferência de 12 de maio de 1722, aludindo às disputas em Roma acerca da publicação da obra do padre Antônio Vieira.

19. CAstello, Aderaldo. Op. cit., p. 40. 
Paus Finos (o Pau-Brasil), Pássaros de várias cores, chamados Pavões na Vulgata" ${ }^{20}$ Já a Segunda parte da Ilustração da América Portuguesa, diz ele, é dedicada a mostrar "como as Influências Celestes, a Região Sublunar, e o Mundo subterrâneo desta América Portuguesa reciprocamente concorrem para o salutífero do Temperamento", originando o ouro e o diamante, a ausência de Vulcanos, e de pestes e epidemias. As palavras de Vieira, acerca de serem os cometas "aviso do Céu" - continua Mateus Saraiva, para quem Vieira é uma autoridade incontornável - são sugeridas pelo seu "afeto Lusitano", que neles achou ocasião para futurizar, como muitos. Mas tanto nas estações do ano como no mapa das constelações, como nas chuvas, se reconhece o salutífero temperamento da América Portuguesa, na qual somente se deve buscar o Paraíso Terreal. ${ }^{21}$ Íris Kantor lembra que "tanto Leibniz como Newton desenvolveram uma visão histórica da natureza, com base em convicções metafísicas e bíblicas sobre a idade da Terra, sem contraporem o mundo histórico ao mundo natural".22 M. Saraiva é um seu digno discípulo, mesclando as exegeses bíblicas - que desde o século Xvi eram aplicadas ao Novo Mundo - às investigações físicas da nova ciência.

Embora as outras obras de Mateus Saraiva citadas na Bibliotheca Luzitana se inscrevam plenamente na racionalidade acadêmica do paragone, isto é, a competição epidítica, aquela que ele apresenta como o maior fruto dos seus esforços, após 29 anos de estudo, é um tratado de medicina, De Re Medica. Junto com umas "Questões com resoluções paradoxas", que remetera a Londres por via do doutor Jacó de Castro Sarmento (médico descendente de cristãos-novos portugueses e membro da Royal Society), devem habilitá-lo a ser introduzido na referida sociedade. Como credencial, menciona ainda uma dissertação astronômica, De re naturali, que é conforme aos "fundamentos do seu grande Isaac Newton, presidente da referida sociedade, e dos do observatório de Paris". ${ }^{23}$ Apesar dos seus estudos de História natural, nem fr. Apolinário, nem Barbosa Machado, nem Jacó Sarmento, ao que saibamos, tiveram sucesso em levar à impressão qualquer das obras do esforçado médico, nem em inseri-lo em qualquer agremiação científica.

Se a lista dos Escritores da Companhia de Jesus no Estado do Maranhão é diminuta - constando nela apenas os nomes dos padres Antônio Vieira, João Phelippe Bettendorf, com a Chronica da Missão dos Padres da Companhia de Jesus no Estado do Maranhão,

\footnotetext{
2o. Idem, p. 43.

21. Idem, p. 51.

22. Ver KANTOR, Íris. Op. cit., p. 73.

23. CAstello, Aderaldo. Op. cit., p. 57.
} 
Aleixo Antonio, que em 1739 compôs uma tragicomédia devota intitulada Hercules Gallicus, Religionis Vindex, e Joseph de Souza, que deixou uma instrução para exame de sacerdotes -, o Cathalogo de alguns escritores desta Capitania do Grão Pará, de 1740, é cuidadoso, escrito com esmero por um calígrafo e assinado por Lourenço Álvares Roxo (1699-1756). Na carta de encaminhamento a d. Francisco, o compilador desculpa-se pela reduzida dimensão do seu catálogo, alegando que ele inclui apenas notícias provenientes do Arquivo do Convento de Santo Antônio do Pará, por não ter tido sucesso em obter mais informações. Apesar disso, não é um rol insignificante e demonstra a pujança literária do Estado do Maranhão e GrãoPará na primeira metade do Setecentos. São também doze os frades elencados, além de um vigário, Antônio Álvares, assistente no coro da Catedral, que escrevera um Vocabulário da língua que se falla no Maranhão. O mais conhecido deles - e mesmo assim tão pouco! - éfr. Cristóvão de Lisboa, irmão de Manuel Severim de Faria, primeiro Custódio de Santo Antônio do Maranhão e Grão-Pará, onde chegou em 1624, aí permanecendo por doze anos. Além dos sermões que imprimiu, fr. Cristóvão escreveu um livro doutrinário, O jardim da Sagrada Escritura, "com hum elenco de discursos, e conceytos sobre os Evangelhos" e uma Historia natural do Maranhaõ, e Graõ Pará, ilustrada, a qual, redigida entre 1624 e 1627, é a primeira descrição da fauna e flora brasílicas. ${ }^{24}$ Ao que se sabe, a tarefa foi-lhe encomendada por seu erudito irmão que, para isso, lhe forneceu "Instruções [...], sobre o modo de como há-de escrever a História Natural e Moral do Maranhão”. A partir delas, sabemos que a Historia natural do Maranhão e Grão Pará era o primeiro de três livros conjugados, sendo que:

no primeiro dedicava-se a dar notícia da região, do clima, da geografia, da natureza, botânica e zoológica, da forma como se deu a conquista. No segundo do descobrimento do Maranhão desde Orelhana, das lutas para expulsar os franceses da ilha de São Luís do Maranhão até à chegada daquele socorro espiritual, em 1624. E por último, no terceiro livro os trabalhos feitos pelos frades, custódio e governador nomeado para o Estado do Maranhão. 25

\footnotetext{
24. Depositada no Arquivo Histórico Ultramarino, foi publicada sob o título História dos Animais, e Árvores do Maranhão em Lisboa, pela Comissão Nacional para as Comemorações dos Descobrimentos Portugueses, em 2000.

25. Luís Filipe Marques de Sousa, "Frei Cristóvão de Lisboa (1583-1652). Vida e Obra do primeiro custódio do Maranhão", p. 43. Comunicação apresentada ao Congresso Internacional sobre os Franciscanos em Portugal e no Mundo, 2011, Sociedade de Geografia de Lisboa - excerto da sua dissertação de mestrado em História e Cultura Brasileira pela Faculdade de Letras da Universidade de Lisboa, Os Capuchos de Santo António no Brasil, 2 vols. (2007).
} 
Como fará d. Francisco de Almeida, o acadêmico, bibliófilo, historiador e antiquário de Évora também ordenava o registro das memórias que, agrupadas, pudessem compor a história dos domínios portugueses. E isso antes dos naturalistas de Maurício de Nassau etc.

O próprio compilador do Cathalogo, d. Lourenço Álvares Roxo de Potflis, chantre da Catedral de Belém, fez um livro à mão sobre os pássaros da Amazônia, hoje depositado no Muséum National d'Histoire Naturelle, de Paris. Um cotejo entre ambos os escritos da fauna do Pará, a cem anos de distância - o de fr. Cristóvão de Lisboa e o de d. Lourenço Roxo - far-se-ia necessário. Segundo Dante M. Teixeira, Nelson Papavero e Lorelai B. Kury, no minucioso artigo "As aves do Pará segundo as 'memórias' de Dom Lourenço Álvares Roxo de Potflis (1752)", ${ }^{26}$ essa parece ser a única parte efetivamente realizada de uma obra sobre os três reinos naturais, intitulada Memórias zoológicas, fitológicas e mineralógicas, ou descrições físico-históricas das mais notáveis produções animais, vegetais e minerais do Estado do Grão-Pará. Ao enviar o Cathalogo a d. Francisco, de fato, d. Lourenço noticia a acalorada redação das suas Memorias, que responde ao empenho de d. Francisco não somente em coletar notícias, como, por assim dizer, suscitá-las: "Fico averiguando outras noticias para outro Cathalogo que remeterey para a primeyra monção querendo Deos, como tambem as memorias Zoologicas, que vou trabalhando nellas com todo o calor, visto V. Exa. Rma. mo ordenar, pois lhe devo em tudo obedecer."

Quase todos os demais escritores que d. Lourenço arrola em seu catálogo são autores de livros manuscritos, como ele mesmo enfatiza, o que só em parte se deve à pobreza dos religiosos, mas, principalmente, ao fim a que se destinam.

quazi todas [as escrituras] manuscriptas; por razão da pobreza dos Religiozos; e por que como saõ em linguas de nasções de gentios a que elles somente se aplicão, e não os das outras relligiões, que apenas trataõ somente da lingua geral; lhes ficão estes livros sendo desnecessarios; e assim somente os capuchos de Santo Antonio se servem delles tresladando-os. [fl. 288]

De fato, a lista é preenchida com nomes de franciscanos, cujos livros são escritos para proveito de suas missões: fr. Boaventura de Santo Antônio, da aldeia de Joannes, escre-

26. Arquivos de Zoologia, Museu de Zoologia da Universidade de São Paulo, vol. 41, n. 2, pp. 97-131, 2010. Uma vez que em 1740 d. Lourenço já menciona a próxima remessa da sua obra, ela deve ser antecipada em doze anos à data de redação conhecida. 
veu um Vocabulario do idioma Sacaca, com a Doutrina Cristã e um Confessionario com admoestações sobre os Mandamentos no mesmo idioma; escreveu também uma Arte da lingua dos Aroás e uma Arte da lingua commua, a que chamam geral, com um Confessionario na mesma língua. Fr. Francisco de Sto. Antônio, versado em Direito, escreveu um oportuno Tratado fobre o meyo mais conveniente para livrar as consciencias dos povos do Maranhão na extracção dos Índios do Certaõ. Fr. Joaquim da Conceição, três Confessionários nas línguas dos povos do Maranhão: Mazaunus, Aroas e Aracajus. Fr. José da Natividade, um Cathecismo da doutrina, e Misterios da nossa Santa Fé para governo espiritual dos índios Aroas, e Maraonus, nessas línguas. Fr. Mateus de Jesus Maria, um Vocabulário da lingua Brafilica; Das coufas mais necessarias aos Missionarios, que assistem entre Gentios; um Cartapacio de Nomes da lingua Maraunii; Praticas sobre os Sacramentos, e Mandamentos, todos na língua geral; um Vocabulário da lingua Aroá, outro Vocabulário com advertências pertencentes à Grammatica da lingua geral, uma Arte da lingua Aroá e um Confessionario na lingua Maraunú. Fr. Pedro de Santa Rosa, um Confessionario na lingua dos Aracujús. E somente fr. Paulo de S. Francisco, comissário Provincial, escreveu uma obra de jurisprudência, Peculio de Direito, que contém varias resoluções de hum e outro Direito, e muitas advertências pertencentes à Pratica Judicial, e Criminal.

Se a alegação da pobreza dos missionários franciscanos é um topos da Ordem Seráfica, ${ }^{27}$ a questão das línguas acerca das quais escrevem é relevante. Não havendo imprensa nos Estados do Maranhão e Grão-Pará, e do Brasil, os escritos dos missionários - que importam ademais para a história dos grupos linguísticos indígenas - não eram suscetíveis de impressão, interessando a um número restrito de religiosos, isto é, apenas àqueles que contatavam os grupos em questão, principal razão pela qual circulavam em cópias manuscritas. Já o conhecimento da chamada "língua geral", o tupi, ao permitir a catequização de um número maior de indígenas, era de maior utilidade e se difundiu na imprensa. Não é despiciendo que o Catecismo brasilico da doutrina christãa, composto por padres da Companhia e ampliado por Bartholomeu de Leão, já citado, enfatize que "Este Catecismo como produsido pelos Portuguezes, he Portuguez na escritura; que pode admitir a penna Portugueza" [Advertencia, s/p.].

27. Ver XAVIER, Ângela. "Les bibliothèques virtuelles et réelles des franciscains en Inde au XVII siècle". Missions dévangélisation et circulation des savoirs XVI $-X V I I I^{e}$ siècles. Madrid: Casa de Velázquez, 2010. pp. 166-88. 
O último texto do códice é um Cathalogo dos Poetas que florecerão na Cidade da Bahia, caligrafado, organizado pelo também poeta Luiz Canelo de Noronha (n.1689). Ao remeter o Cathalogo a d. Francisco, o pe. Plácido Nunes, na carta supracitada de 1738, avalia o critério do organizador da lista, explicitando as providências que tomou relativamente a ela:

O [catálogo] dos poetas Seculares fello na mesma forma, em que o remetto, hum poeta desta Cidade, que tambem nelle se fez lugar. Eu para dizer a Vossa Senhoria a verdade, entrey em pensamentos de o desbastar; mas deixeime disso, por naõ saber a idea, que Vossa Senhoria segue na sua obra. O certo hê, que o author deo o nome de poeta a muitos, que, ao que entendo (conheço os mais delles) apenas saberaõ fazer hum quarteto. Ao menos nem merecem ter lugar entre os poetas, nem na penna de Vossa Senhoria. Resolvime pois à distinguillos nesta forma: aos que Vossa Senhoria pode admittir sem escrupulo, notey-os à margem com a letra $\underline{\mathrm{A}}$. Aos que julguey menos dignos deste choro com a letra $\underline{\mathrm{R}}$. Vossa Senhoria seguirà o que lhe parecer. Advirto porem a Vossa Senhoria, que nem a todos os que levaõ $\mathrm{o} \underline{\mathrm{R}}$ dou o titulo de maos poetas: Sô quero insinuar, que se não deve fazer menção delles, huns certamente por ruins, e outros por naõ terem composto couza, que avulte [fl.148].

Com efeito, o Cathalogo lista 39 poetas, todos naturais da Cidade da Bahia ou do seu Recôncavo, ao lado de cujos nomes constam as letras $A$ ou $R$. Vinculado à concepção dos catálogos retóricos de "excelentes em seu gênero", ${ }^{28}$ e desconhecendo o conceito que unificaria o conjunto ("por naõ saber a idea, que Vossa Senhoria segue na sua obra"), o pe. Nunes acha por bem distinguir aqueles que reputa por bons e aqueles que por maus poetas, não sem reparar que o critério reside não numa essência atemporal, mas na oportunidade da escritura ("por naõ terem [ainda] composto couza, que avulte") e no gênero da escritura ("o author deo o nome de poeta a muitos, que, [...] apenas saberaõ fazer hum quarteto"). Deste modo, reprova como poetas o historiador Sebastião da Rocha Pitta, o secretário de Estado Gonçalo Ravasco e o novelista Nuno Marques Pereira (ou Marques da Silva, como nomeia), e outros muitos, ao passo que aprova, apenas: Bernardo Vieira Ravasco, Manuel Botelho de Oliveira, os irmãos Gregório,

28. Ver "Pela mão dos curiosos: livros de poetas na Bahia setecentista", em que analiso especificamente esse Catálogo. Aí, desenvolvo a diferença entre os exempla de autoridade e os inventários de escritores, bem como a oportunidade da redação desse Catálogo no âmbito da lembrança da Academia dos Esquecidos e na esteira do governo do vice-rei Vasco Fernandes César de Meneses. 
Eusébio e Pedro de Matos, Gabriel Vieira, Gonçalo Soares da Franca, o pe. João Álvares Soares, João de Almeida Teles e Minaya, João de Brito e Lima, fr. Agostinho de N. Sra. do Monte do Carmo, e os irmãos André, João e José de Figueiredo Mascarenhas. Em suma, o pe. Nunes escolhe apenas os melhores frutos da terra para enviar à corte, e nunca, aliás, frutos enxertados, de epopeias e prosas, de discutíveis propriedades.

O próprio organizador do Cathalogo, por sua vez, o poeta Luiz Canelo de Noronha, antigo membro da Academia dos Esquecidos, mais aderido tanto ao conceito de um elenco de poetas lato sensu, como ao de uma "Biblioteca da América Portuguesa" (podemos assim dizer), lista todos aqueles que, tendo escrito na arte poética, são naturais do Recôncavo da Bahia, capital do Brasil. Se lemos bem, na aparente penúria de informações do Cathalogo compatível entretanto com os propósitos inventariantes da Academia Real -, elas indicam o quanto importa saber acerca dos poetas (pátria, pais, ofício) e de suas obras: os gêneros (oitavas, décimas, loas, bailes, comédias, sonetos, romances, novelas, poemas heroicos), a língua (latina, ou vulgar), a ocasião (na Academia do Conde de Sabugosa, ou na de Diogo Pereira da Silva), ${ }^{29}$ e, se foram impressos, em que tamanho, ou se correm manuscritos. Aqui, é menos sua individualidade como poetas o que se salienta, do que seu pertencimento ao conjunto, que, por copioso e vário, atesta a excelência das letras da capital do Brasil.

O critério espacial subjacente a essa lista é relevante. Na Bibliotheca Lusitana ele circunscreve, em termos de centro e circunferências, os territórios que gravitam em torno de Lisboa, os da África, da América e da Ásia, aparentemente desierarquizados entre si, em razão do aleatório critério alfabético. Com isso, a Bibliotheca exibe os naturais daqueles territórios como componentes que amplificam e enaltecem o, sem eles, pequeno reino de Portugal. O que importa é, pela acumulação, apresentar o “vergel”, ou “jardim” de letrados, cuja qualidade reside na própria quantidade de seus elementos; não é do seu escopo assinalar a preeminência de um escritor sobre o outro (salvo, em raras ocasiões, um elogio mais enfático acerca de Vieira, ou outro autor maior), sendo que o único critério necessário para um nome comparecer na Bibliotheca é "haver escrito algo em algum lugar". Ao registrar apenas os poetas naturais da Bahia - poetas em verso e poetas em prosa -, Luís Canelo demarca-se dessa e das demais classificações vistas: a ratio da sua lista não está na escolha dos excelentes, não depende de uma inscrição religiosa, nem de uma subor-

29. Ainda não obtive qualquer referência a esse êmulo do vice-rei, filho do médico Manoel de Matos de Viveiros, que "fazia Academias em sua caza com sumptuozidade e gasto" (fl.334v). Os poetas Antônio Lopes de Ulhoa e Jerônimo Rodriguez de Crastro (Reprovados...) eram dos que acorriam a ela. 
dinação direta à empresa acadêmica: restringe-se à naturalidade comum dos escritores e ao gênero da sua escritura. De certo modo, Luís Canelo partilha da mesma concepção da Bibliotheca Lusitana, exceto por limitar o "algo" aos gêneros poético-retóricos, o "lugar" a um território demarcado, a Bahia, e a relação entre eles, ao "florescer".

No códice 7187 da BNP, reencontramos o pe. Plácido Nunes, no ano seguinte, após a correspondência de d. Francisco acusando o recebimento dos dois catálogos, o dos escritores da Companhia e o dos poetas da Bahia. Atendendo ao desejo do encomendador, o padre providencia-lhe a remessa de manuscritos que julga dignos do panteão poético de Lisboa, os poucos que floresceram e frutificaram:

Estimo que o Catalogo dos escritores fosse a gosto de Vossa Excellencia. No que toca aos Manuscritos remetto a Vossa Excellencia os que julguei dignos de attenção. Poucos são, bem o vejo; mas irâ contra o clima do Paiz, donde he natural a Preguiça, quem destes engenhos quizer mais. Certamente que por ca mais se obra, do que se escreve. Vay a poezia do P. Prudencio d'Amaral, não das frutas do Brazil, como Vossa Excellencia dizia, mas de Opificio Sacchari. Nella verâ Vossa Excellencia hum pequeno rasgo da precioza tela que trajava aquella nobre Muza [fl.19].

Na primeira metade do Setecentos, recolhem-se as memórias - poéticas, históricas, zoológicas, minerais -, as quais se agrupam em ordens, de semblante caótico apenas para quem persegue outra racionalidade. A do pe. Nunes remonta à dos homens ilustres e feitos heroicos dos séculos anteriores ("Outros muitos hâ por maons particulares, mas naõ os julgo dignos de memoria"). ${ }^{30}$ A ratio da Academia Real da História, porém, cristalizada na Biblioteca Lusitana, é a da coleção compósita, demonstrativa de uma República das Letras: aglutinando as heteróclitas memórias particulares num único e vasto edifício, em que haja lugar para todos - não obstante uns detenham mais espaços do que outros... Assim, pôde agrupar as memórias dos franciscanos, dos jesuítas, dos beneditinos, dos dominicanos, das freiras, dos poetas, dos homens de ciência, dos visionários, dos que escreveram sobre teologia polêmica, dos que nasceram em África etc. etc., sendo a unidade plural retrato de uma monarquia estendida pelas quatro partes do mundo. Não à toa, Mateus Saraiva, o físico do Rio de Janeiro, se associava ao padre Atanásio Kircher, que professava conjuntamente o ensino da física, das matemáticas

3o. Cód. 1787, fl.21. 
e das línguas orientais e coligia dos missionários das Índias, a oriental e a ocidental, objetos para o seu Museu.

Na coleção reunida por Kircher no Colégio Romano havia estátuas antigas, objetos pagãos de culto, amuletos, ídolos chineses, tábulas votivas, duas telas com as cinquenta encarnações de Brahma, inscrições sepulcrais romanas, lucernas, anéis, fechos, fivelas, armilas, pesos, sonetas, pedras e fósseis, sobretudo com imagens produzidas pela natureza, um aparato de objetos exóticos ex varii orbis plagis collectum, contendo cintos de indígenas brasileiros enfeitados com os dentes das vítimas devoradas, pássaros exóticos e outros animais embalsamados, livro malabarense em folhas de palmeiras, artefatos turcos, balança chinesa, armas bárbaras, frutos indianos $[\ldots] .^{31}$

Não à toa, fr. Apolinário da Conceição faz imprimir o Triunfo Eucarístico, "Dedicado à Soberana Senhora do Rosário pelos Irmãos Pretos da sua Irmandade e à instância dos mesmos, exposto à pública notícia", o qual exibe à corte de Lisboa a implantação do cristianismo nos negros da "corte da Capitania das Minas" (como consta na sua folha de rosto). Nem é por acaso que d. Lourenço Roxo, chantre da Catedral do Pará, salienta os Vocabulários das duras ou melodiosas línguas indígenas, e escreve acerca dos pássaros que ouve cantar. Tampouco é à toa que haja tantos livros de poetas no Recôncavo baiano, onde concorrem duas Academias, ambas esquecidas. A América Portuguesa teria uma história para contar.

Adma Fadul Muhana é professora livre-docente de Literatura Portuguesa na usp. Entre seus livros estão: Os Autos do processo de Vieira na Inquisição (1995), A epopeia em prosa seiscentista (1997), Poesia completa de Manuel Botelho de Oliveira (2005), Infortúnios trágicos da constante Florinda (2006) e Uriel da Costa e a nação portuguesa (2017).

31. ECO, Umberto. A vertigem das listas. Rio de Janeiro: Record, 2010, pp. 203-4. 